\title{
RETINITIS PIGMENTOSA AND RETINITIS PUNCTATA ALBESCENS
}

\author{
BY
}

\author{
J. G. MilneR \\ LONDON
}

THE following cases seem to be worth reporting, as they show some interesting features.

\section{Case I}

Mrs. S., aged 22 years, came to see me in August, 1931, complaining of night-blindness. This she had had as long as she could remember, and she wanted to know if anything could be done.

Past History.-Apart from night-blindness there was nothing of note. She does not think that her complaint has progressed at all since she was a child.

Family History.-Her mother has been blind for eleven years. (For details of her condition see Case II.) Her father is dead, but as far as is known, his sight was good. She is the only child of this marriage. Her mother has married again, and has four children by her second husband. I have not yet had an opportunity of examining them. There was no blood relationship between her parents.

The patient is married, and there was one child, who died in infancy from broncho-pneumonia. So far as she knows, this child saw well.

Present Condition.-She is a healthy woman, with fair hair and a fair complexion. Vision in each eye is $6 / 18$, and with hypermetropic correction, 6/6. The fundi present an appearance typical of retinitis punctata albescens. Small, discrete, whitish spots are scattered all over the fundus, the discs are normal in appearance, and the vessels not diminished in calibre. No lens or vitreous opacities are visible with the ophthalmoscope.

The visual fields are concentrically contracted, rather more of the lower half of the retina being involved in each eye.

\section{Case II}

Mrs. B., aged 41 years, mother of Case I. I saw her at St. Bartholomew's Hospital, in October, 1931.

Past History.-As long as she can remember, she has been night blind, and for the past ten or eleven years, has been more or less completely blind. Her sight failed gradually. 
Family History.-Details of this are not very complete, but her mother went blind at about the age of 50 years, with a previous history of night-blindness. Her maternal grandfather was also night-blind. She has two brothers living, both of whom are affected, but I have been unable to get into touch with either.

Present Condition.-This woman has brown hair and a medium complexion. Her left eye is totally blind, the lens is opaque. There is faint perception of light in the right eye, with a very sluggish pupil reaction. In the fundus there is extensive retinitis pigmentosa, reaching from the periphery right up to the disc. The vessels are thin, and the disc itself has that colour typically described as waxy. There is a shallow retinal detachment below. There are vitreous opacities, and peripheral and post-cortical opacities in the lens.

\section{Case III}

Miss F. W., aged 17 years, was brought to St. Bartholomew's Hospital by her mother to see Dr. Carmichael on account of twitching movements of one side of her body. A diagnosis of hemichoreiform movements was made, and she was referred to the ophthalmic department for an opinion on some changes in the fundi.

Past History.-She is a deaf-mute, but is intelligent, and has done well at school. Her general health has been good.

Family History.-Her mother and father are alive and well. They are first cousins. I have examined them both, and their fundi are normal. There are two other children, a man aged 23 years, who has good vision, and is normal in every way, and a boy of 13 years, who is a deaf-mute. (See Case IV).

Present Condition.-This girl has light brown hair, and a medium complexion. She has myopic astigmatism, and with correction, vision appears to be about $6 / 18$ in each eye. Both fundi show well marked retinitis pigmentosa, with narrowed arteries and waxy discs. There are vitreous opacities, but no lens opacities. I was unable to obtain an accurate visual field chart.

\section{Case IV}

C.W., aged 13 years, brother of Case III. I saw this boy at St. Bartholomew's Hospital also. He is a deaf-mute, is intelligent, and has always been healthy.

Present Condition.- He has very fair hair and a fair complexion. Vision, with glasses, is right, $6 / 12$, left $6 / 12$ partly. The fundi show, at the periphery, a few scattered "bone-corpuscle" shaped pigment spots. In addition, there is a large number of yellowishwhite spots scattered all over the fundi. The discs are of a normal colour, and the vessels of normal size. There are a few vitreous 
opacities in each eye, but no lens opacities. The visual fields are very restricted.

The Wassermann and Sigma reactions were examined in the blood of all four cases, and proved in each to be negative.

It is interesting to note the occurrence of retinitis punctata albescens in a woman whose mother is blind from retinitis pigmentosa. Nettleship ${ }^{1}$ quotes cases of the two occurring in members of the same family, and others have been described. As one would expect, the disease in the daughter appears to be stationary, whereas in the mother it has progressed to blindness. It will be noticed that the onset of blindness in this particular case was rather earlier in life than usual, i.e., about 30 instead of 45 or 50 years of age.

In the other family it seems odd that the eldest child should be quite normal, while his brother and sister exhibit such hereditary taints as deaf-mutism and retinal degeneration. Furthermore, the fundus appearances of the two are different. The girl is an example of typical retinitis pigmentosa, the boy is not; although his visual fields are restricted up to the $10^{\circ}$ circle, there is very little pigment, and what there is, is confined to the periphery. The discs are not waxy, nor are the vessels diminished in calibre; in the girl both these factors obtain. The small yellowish-white spots, scattered all over the fundi of the boy, are absent from those of his sister.

Nettleship has stated that retinitis punctata albescens is a variety of retinitis pigmentosa, and this is generally accepted. It follows that the pathology of the two conditions must be closely related. Opportunities of examining eyes with retinitis punctata, pathologically, seem to have been very few. I can find one case, quoted by Pascheff, ${ }^{2}$ in which Wedl and Bock examined, histologically, such an eye. They concluded that the disease was due to oedema of the retina, and they found that there was evidence of inflammation of the external retinal layers. Gayet and Fuchs did not agree with this interpretation, and suggested that disappearance of the pigment in the region of the spots wass responsible. The matter is not yet clear, nor are we yet agreed upon the pathology of retinitis pigmentosa. In considering my few cases, I was struck by the fact that Cases I and IV were lacking in pigment, as evinced by their very fair hair and complexion. One of these had retinitis punctata albescens, and the other, a change which seems to me to be intermediate between this and retinitis pigmentosa, being typical of neither. It seems possible, therefore, that a relative poverty or excess of pigment cells in the body, would manifest a similar poverty or excess in the retina, and given the necessary hereditary factor, whatever that may be, would be responsible for the type of fundus change in any given case. In this connection it may be mentioned that $\mathrm{Healy}^{3}$ states that retinitis punctata albescens is 
due to abnormal pigment deficiency. I cannot call to mind a case of retinitis pigmentosa in a very fair person, but $I$ have seen too few examples of retinitis punctata to be sure of the opposite.

In conclusion, my thanks are due to Mr. Foster Moore for permission to report Cases II, III and IV.

\title{
REFERENCES
}

1. Nettleship.-Koy. Lond. Ophthal. Hosp. Reports, Vol. XVII, p. 390, 1907.

2. Pascheff.-Ophthal. Rev., p. 65, 1905,

3. Healy.-Brit. Jl. of Ophthal., p. 18, 1921.

\section{TWINS WITH EYE DEFECTS-AMETROPIA AND STRABISMUS}

\author{
BY \\ J. A. Wilson \\ CAMBUSLANG, GLASGOW
}

THE following twelve pairs of twins have been seen in the course of ordinary school and other eye-work. As they have been ophthalmologically selected they may not meet the strict requirements of the specialist in biometrics, yet their manifestations may be of some value.

The evidence of heredity found in uniovular, or monozygotic twins is naturally of great value. Information on the character of the pregnancy relative to this question is seldom available for the biometricians and for diagnosing mono- from dizygotic twins; they have to depend on height, weight, facial resemblance, colour of hair and eyes, head measurements and finger-prints.

The refraction of the eyeball estimated by retinoscopy, the curvature of the cornea taken by the ophthalmometer and the presence, or absence, of strabismus, in all pairs thought to be monozygotic should be made available for the biometricians. Sufficient information on these points would probably decide whether departures from emmetropia (hypermetropia, myopia and astigmatism) and strabismus, are due to heredity or to environment, to nature, or nurture.

It is impossible to say how many pairs in my series are monozygotic, yet all the pairs are of like sex and as in several pairs the retinoscopies are alike, it may be reasonable to assume that one-half are of monozygotic origin.

If we get, say, 4 dioptres of hypermetropia in one twin and 5 dioptres in the other, or 6 dioptres of myopia in one twin and 7 dioptres in the other, then probably these should be classed as being alike, but I have not done so. 